\title{
Industry 4.0 and environmental accounting: a new revolution?
}

\author{
Roger Burritt ${ }^{1 *}$ and Katherine Christ $^{2}$
}

\author{
* Correspondence: \\ roger.burritt@gast.uni-kassel.de \\ ${ }^{1}$ Management in the International \\ Food Industry, Faculty of Organic \\ Agricultural Sciences, University of \\ Kassel, Steinstraße 19, 37213 \\ Witzenhausen, Hesse, Germany \\ Full list of author information is \\ available at the end of the article
}

\begin{abstract}
The paper seeks to examine how, through environmental accounting, the broader context of corporate sustainability could be incorporated into the developing vision for Industry 4.0, the fourth industrial revolution. An argument is developed that through engagement of the profession environmental accounting could be enhanced and could piggy-back at little extra cost on large actual and potential investments being made in Industry 4.0 infrastructure designed for digitisation of business. Industry 4.0 could be used successfully as a basis upon which to leverage both external environmental accounting and environmental management accounting. A new academic research program is suggested aimed at establishing how Industry 4.0 might facilitate more accurate, high quality, real time environmental management accounting and external environmental reporting in relevant sectors, company sizes, across different management roles and collaborative settings, as well as in supply and value chains. Ways are outlined in which accountants, professional associations and government can help capture the benefits of Industry 4.0 for environmental accounting. These include education and training opportunities and building on efficiency and lower cost notions which are a key part of Industry 4.0. This innovative paper provides first research into the potential of current and expected large investments throughout the world in Industry 4.0 to provide a foundation for improvements in corporate sustainability through greater take up of environmental accounting.
\end{abstract}

Keywords: Industry 4.0, Environmental accounting, Environmental management accounting, External environmental reporting, Internet of Things, Internet of Services, Cyber-physical Systems, Transdisciplinarity

\section{Background}

The previous three decades have brought a burgeoning interest in corporate sustainability to the fore. Not only are members of the public demanding organisations treat natural resources such as water, air, and soil with respect, government and nongovernment organisations are encouraging corporations to undertake activities in a manner that is economically, environmentally and socially sustainable. However, beyond the need to satisfy external stakeholders, organisations have also begun to realise the benefit associated with proactive environmental activity.

In 1995, Porter and van der Linde argued that pollution equates to inefficiency and that inefficiency is in turn a source of economic disadvantage. Thus pollution prevention represents an opportunity for business entities to improve their financial performance through, for example, enhanced productivity and innovation. The work of Porter

(c) The Author(s). 2016 Open Access This article is distributed under the terms of the Creative Commons Attribution 4.0 International License (http://creativecommons.org/licenses/by/4.0/), which permits unrestricted use, distribution, and reproduction in any medium, provided you give appropriate credit to the original author(s) and the source, provide a link to the Creative Commons license, and indicate if changes were made. 
and van der Linde (1995) was an important step towards establishing what has become known as the 'business case' for sustainability. Their work challenged the long held belief that acting 'environmentally' could only ever be seen as a source of expense.

Notwithstanding the aforesaid shift in conventional thought, in reality the notion of environmentally friendly action as a potential business opportunity was not always intuitive to managers. Thus there was a need for tools to be developed that would allow them to assess how their organisation is impacted by environmental matters and how in turn, it impacts the environment in which it operates. This need gave rise to the development of environmental accounting in the 1990s. Environmental accounting goes beyond generic environmental management as it encourages an integrated approach to economic and environmental control which allows win-win scenarios, and sometimes potential trade-offs, to be identified and an appropriate course of action selected.

There is no denying environmental accounting has come a long way in 30 years. Nonetheless, many studies still report a lack of engagement on the part of business entities. One reason for these observations may be a lack of appropriate data, or the technology to collect appropriate data, combined with the inherent complexity of corporate sustainability as a concept (Searcy and Elkhawas, 2012; Wiedmann and Barrett, 2010). Lack of timely and accurate data could undermine the credibility of environmental accounting efforts in the long-term and render the practice open to accusations of greenwashing (Hsu et al., 2013). However, the industrialised world is on the cusp of a new stage in its evolutionary development which looks set to change the nature of environmental accounting forever: Industry 4.0.

Industry 4.0, sometimes referred to as the fourth industrial revolution or Internet of Things, is a concept that originated in Germany (Davies, 2015). In short it is argued that advanced information technology and social media networks will allow businesses, facilities and machines throughout the value chain to share data in real time and use smart networks to develop a level of self-awareness that was not previously possible. This will allow the machines that manufacture products themselves to "suggest task arrangements and adjust operational parameters to maximise productivity and product quality" (Lee et al., 2014, p. 5). To date focus on the development of Industry 4.0 has been on reduced errors, improved product quality, freeing humans from menial and/or dangerous tasks and providing consumers with the products they desire at times when they desire them. Resource efficiency is also mentioned but an understanding of how the broader context of corporate sustainability could be incorporated into this agenda, remains underdeveloped. This paper seeks to examine this issue in the context of environmental accounting. In doing so the following research question will be considered:

\section{How might Industry 4.0, or the Internet of Things, be employed to enhance the outcome of environmental accounting initiatives?}

The paper proceeds as follows. Problems with environmental accounting initiatives section examines the data gathering problems of environmental accounting techniques. An overview of Industry 4.0 is provided in the Overview of industry 4.0 section. Using the impetus from industry 4.0 for environmental accounting section explores how to capture the impetus of Industry 4.0 to contemplate enhancements in environmental 
accounting, while Discussion - capturing the potential of industry 4.0 for environmental accounting section concludes the paper.

\section{Problems with environmental accounting initiatives}

Although it has grown in popularity a number of problems with environmental accounting have restricted stakeholder interest and management take-up of the techniques thus far. These problems relate to the two interrelated components of environmental accounting: external environmental accounting and environmental management accounting (Schaltegger and Burritt, 2000). The former delivers environmental accounting information to external stakeholders while the latter provides support for decisions made by internal managers.

External environmental accounting was developed because environmental issues were growing in importance and conventional financial accounting did not separately identify, classify and measure environmentally related impacts on the economic situation of companies (Schaltegger et al., 2003). Neither did conventional financial accounting record in physical terms company-related impacts on environmental systems. But data quality and measurement problems in external environmental accounting mean comparability and reliability of reported environmental data are compromised. The availability and quality of external environmental accounting disclosures remain locked into the problems of greenwash and brownwash.

Greenwash is where corporate environmental performance is overstated (Deegan and Rankin, 1996), whereas brownwash is where green credentials are understated (Kim and Lyon, 2014). For example, greenwash is possible when stakeholders have no direct measures of greenhouse gas emissions and rely on managers to address modeling complexity, estimation processes and assumptions made behind data disclosed. Management have discretion as to whether to recognise greenhouse gas emissions, and whether and how to manipulate measures and perceptions of greenhouse emissions (Hrasky, 2011). Likewise, brownwash is encouraged by fear of adverse stock market reactions to emphasis being placed on environmental performance, such as winning green awards, rather than monetary performance (Kim and Lyon, 2014). Both greenwash and brownwash can diminish the usefulness of external environmental accounting initiatives in the eyes of stakeholders as management retain considerable discretion over the environmental issues to recognise, how to measure these, and what to disclose. Skepticism about the veracity of reported environmental accounting disclosures leads to lost credibility of the data.

Problems of environmental management accounting in guiding management decisions largely relate to the unavailability and poor quality of data, the need to change information gathered by extant management control systems, and the need to introduce infrastructure for information gathering and sharing in supply chains (Kokubu and Kitada, 2015). In environmental management accounting data is gathered to identify win-win settings in organisations where both economic and environmental performance can be improved (Burritt et al., 2002). Such improvement can be calculated as eco-efficiency, a relative measure used to compare economic and environmental performance e.g. dollar sales per tonne of carbon emissions. If eco-efficiency data is missing, inaccurate or of poor quality, then there is less incentive for managers to adopt 
environmental management accounting as calculations will be unreliable and profitable opportunities which support improvement lost.

Various environmental management accounting data problems have been recognised. Ten years ago the International Federation of Accountants in its guidance document on environmental management accounting warned:

"Although larger companies annually generate millions of data records concerning material movements from Enterprise Resource Planning (ERP) and other software systems, the available information often is still not sufficiently accurate or detailed for environmental, efficiency and other decision-making purposes" (IFAC, 2005, p. 27)

The International Federation of Accountants (IFAC, 2005) in particular highlighted that material use, flow and cost data were not being adequately identified and tracked. Instead they suggested that following their guidelines might encourage adoption of reliable data for eco-efficient decision-making. Although no assessment of adoption of the International Federation of Accountants guideline has since taken place others have commented on data problems. In the early days of environmental management accounting Epstein (1996) observed "...careful identification and tracking of all environmental costs have often produced totals that are four or five times the estimates" (p. 12).

The complexity of obtaining environmental cost data is illustrated by Ditz et al. (1999) who in an early study spent 6 months at Yorketown Refinery in the USA to establish that environmental costs were inaccurately estimated as $3 \%$ of non-crude operating costs when actual calculations revealed them to be $22 \%$. The U.K. provides another example of poor estimation where it was found the actual cost of waste to be on average 25 times that estimated in the sample of businesses examined (Phillips et al. 1999).

In the context of carbon management accounting, a theme specific sub-set of environmental management accounting, Burritt et al. (2011) recently discovered from a set of interviews with managers in Germany that the large variety of departments and types of professionals involved meant ad hoc rather than systematic data had to be gathered in spite of the resulting poor data assurance and process inefficiency. Accountants were not comprehensive information gatekeepers:

“...carbon information is not generated in a single department; instead, engineers, plant managers, and other functional managers below the level of top management have extended their duties and are engaged in the generation and dissemination of information." (Burritt et al., 2011, p.90)

With the one exception of regulated emissions trading systems where new appointments were made to ensure data gathering and management:

"Variability was found to depend closely on the organisational structure of the company regarding carbon-related information management and usage, and organisational structure for carbon information collection was closely related to 
the various purposes of the information collected. Whereas some of the companies need such information solely for legal compliance, others use it to adjust their operating costs and still others use it for long-term planning." (Burritt et al., 2011, p.90).

There has been slow development of tools to encourage managers to obtain data on environmental costs and losses, the identification and size of which were a key stimulus to development of environmental management accounting so that once identified they could be managed and reduced (US EPA, 1995). It was only in 2011 that a voluntary environmental management standard for Material Flow Cost Accounting, ISO 14051, to reduce physical waste and cost from materials resources use became available (Christ and Burritt, 2015; ISO, 2011). The tool, which also includes water and energy, provides a systematic way in which to gather physical and monetary material flow information. Although monetary measures of material losses are a key part of Material Flow Cost Accounting to assist with eco-efficiency calculations linking economic and environmental performance, problems remain as management resist being accountable for such losses. Toyota's Kaizen system is illustrative as material losses are not accepted as a part of continuous improvement targets (Kokubu and Kitada, 2015). As Scavone (2006) points out in Argentina very few companies have been able to integrate environmental actions into their broader management systems. Likewise, Kokubu and Kitada (2015) identify only three such companies in Japan. Scavone (2006) identifies this lack of integration to be a major obstacle for the generation of assessable information about environmental and economic performance. Furthermore, in countries such as Lithuania companies do not fully estimate their waste streams, with opportunities to improve environmental and financial performance through better informed operations and investment decisions being lost (Staniskis and Stasiskiene, 2006).

When suitable data is unavailable environmental costs can also be transferred between departments, or between parties in supply chains leading to lost opportunities and a need for suitable cost-effective technological infrastructure to help gather and share environmental management accounting information. Evidence from Burritt et al. (2011) indicates that within top German companies sampled information about the effects and successes of carbon emissions is not transferred between departments, rather a silo mentality exists whereby managers focus on the carbon consequences of their own departments. Similarly, Viere et al. (2011) identify the need for investing in supply chain information systems in the coffee industry to support decision making between parties if environmental management accounting is to provide necessary support for eco-efficient decisions.

In short, the discussion about problems with EA considered above accords with Brown et al.'s (2005) view that to meet the environmental imperatives of the future requires better information technology and richer information. The next section considers the emergence of Industry 4.0, which might provide a foundation for overcoming these challenges.

\section{Overview of Industry $\mathbf{4 . 0}$}

Industry 4.0 is an umbrella term used to describe a group of connected technological advances that provide a foundation for increased digitisation of the business 
environment (Davies, 2015; Kagermann, 2015). Baur and Wee (2015) recognise four characteristics of and disruptions stemming from Industry 4.0:

“...the astonishing rise in data volumes, computational power, and connectivity, especially new low-power wide-area networks; the emergence of analytics and business-intelligence capabilities; new forms of human-machine interaction such as touch interfaces and augmented-reality systems; and improvements in transferring digital instructions to the physical world, such as advanced robotics and 3-D printing".

Industry 4.0 is driven by improved data gathering processes enabled by transistors in integrated circuits doubling in capacity every 2 years (called Moore's Law), thereby lowering cost of digital electronics, reducing size of components, facilitating portability and increasing availability of data through connected machines (Deloitte, 2015).

Key concepts underlying Industry 4.0 are increased connectivity of networks using the Internet of Things and Internet of Services through Cyber-Physical Systems. The Internet of Things is the network of physical devices (things) embedded with networked microchip technology, software, sensors and controllers enabled to collect and exchange data, while the Internet of Services is the offering of services through the internet. Cyber-physical systems are physical things monitored and controlled wired and wirelessly by computer-based (cyber) algorithms (Deloitte, 2015) through artificial (non-human) intelligence to trigger automated action (Atzori et al., 2010). In smart factories of the future it is anticipated that sensors will monitor the physical environment and computer algorithms be used to control physical operating parameters. The result would be a manufacturing environment which has "self-awareness, self-prediction, selfcomparison, self-reconfiguration, and self-maintenance" (Lee et al., 2014, p. 4). Typical would be Philips Electronics' advanced manufacturing of 600 models of electric shavers in the Netherlands, which optimises economic efficiency in a factory with 128 robots and only nine workers there to provide quality assurance (Davies, 2015, p. 5).

Industry 4.0 is a vision of industry as it could be in the future or rather an aim to work towards, and not the industry of the present (Baur and Wee, 2015; Deloitte, 2015). Initially, Industry 4.0 was seen as a way for Germany to maintain a competitive advantage over emerging economies which have lower labour costs (Davies, 2015). The notion quickly spread in the European Union, the USA, and Asia/Pacific regions, especially in China, Russia and Brazil (Staufen 2016).

Commentators recognise there are no guarantees over the rate of take up of Industry 4.0 technologies and the benefits which might be secured. They speculate about anticipated large changes ahead with claims such as "The rise and fall of enterprises and entire national economies will hinge on making 'intelligent factories' a reality" (Wübbeke and Conrad, 2015), and "[Industry 4.0] is just beginning to take off and it's difficult to imagine exactly how it's all going to develop" (Gray and Hughes, 2016). Davies (2015, p. 5) advising the European Union warns "Industry 4.0 as a concept is poorly defined and suffers from exaggerated expectations".

Notwithstanding this scepticism, large amounts of money are being invested by governments and business to try and make the Industry 4.0 vision a reality. Predictions have been made of US\$15 (A $\$ 20)$ trillion being invested in the industrial internet, the 
US equivalent term for Industry 4.0, by 2030 (General Electric Company and Accenture, 2015). Under the Horizon 2020 research program between 2014 and 2020 the European Union has already committed almost $€ 80$ (A $\$ 118$ ) billion for research and innovation, including support for developing key enabling technologies and made available at least $€ 100$ (A $\$ 145)$ billion for investment in innovation from European Structural and Investment Funds (Davies, 2015). Europe is predicted to need investment of $€ 140$ (A \$200) billion each year with Germany providing $€ 40$ (A\$60) billion of the annual total (Davies, 2015). China is experimenting with Industry 4.0 technologies through CNY 500 (A $\$ 100)$ billion of government funded support at national and regional levels (Gray and Hughes, 2016). Through its 'Made in China 2025' policy the state promotes the digitisation of the industry with elaborate support programmes for the Internet of Things, robots, intelligent manufacturing systems, cloud computing and the transformation and upgrading of industry (Gray and Hughes, 2016). Almost 60\% of manufacturing companies in China have Industry 4.0 on their agenda, compared with the world leader, Germany, with almost $80 \%$ (Staufen, 2016).

This fourth industrial revolution has been promoted as providing annual efficiency gains from resource productivity in manufacturing of between 6 and 8\% (Davies, 2015), greater capital intensity and more flexible models of work organisation (Germany Trade and Invest, 2014) through improvements in machine to machine information and communication technologies. Nonetheless, in Switzerland the anticipated relative advantages over low labour-cost developing country production is now recognised as unlikely to stem the flow of offshore activities (Deloitte, 2015), with the future direction of Industry 4.0 development viewed as speculative at best (Gray and Hughes 2016). Furthermore, competition from China is accompanied by proposed moves towards becoming the world's leading industrial power by 2049 , when the country turns 100 (Staufen, 2016). China intends to catch and overtake other countries in the near future and recognises networked production, in which machines and parts are engaged in an ongoing exchange of information, to be essential (Staufen, 2016). But progress is limited by the lack of standards for the language used by chips to communicate with each other, lack of know-how, poor legal standards for data protection which will slow take-up, and insufficient capital to invest in technology (Staufen, 2016). Nevertheless China is putting its full weight and funding behind the integration of industrialisation and informatisation (Wübbeke and Conrad, 2015).

Given the problems outlined in Problems with environmental accounting initiatives section, and the potential from new information and communication technologies being introduced into advanced manufacturing the paper turns to consider how Industry 4.0 might be used to improve current environmental accounting initiatives.

\section{Using the impetus from Industry $\mathbf{4 . 0}$ for environmental accounting}

Industry 4.0 might be used to improve both external environmental accounting and environmental management accounting if extensive digitisation occurs in a fourth industrial revolution.

Potential improvements in external environmental accounting initiatives from Industry 4.0 could include: 
- Better data quality - improved timeliness, accuracy, reliability and comparability of reported environmental accounting data

- Reduced opportunity for greenwash and brownwash

- Less management discretion over what is measured, and how it is measured and reported

- Higher credibility of data.

In an Industry 4.0 digitised smart network setting "machines are connected as a collaborative community" (Lee et al., 2014, p. 3) exchanging massive quantities of actual data available in real time, not estimated, averaged or influenced by human involvement. Such data is referred to as providing 24/7/365 digital real- time transparency of performance measurement and reporting both for managers and external stakeholders (Seele, 2016). This means data is available immediately (real time) at every moment of every day ( 24 h, 7 days a week and 365 days a year). Availability of real time data is already being promoted through the introduction of XBRL as a financial reporting language to improve accuracy, reliability and, in consequence comparability, of reported data and could be extended to non-financial data:

...corporate executives as well as regulators and external stakeholders (if data were published instantly) could react immediately in making informed decisions on relevant data points (Seele, 2016).

In technical terms the digitisation of data gathering and reporting in real time also means there is potentially less opportunity for greenwash and brownwash for three main reasons. Management discretion over the migration of mass data is removed as transfer to the common repository is in real time, through digital means data in the common pool can be made available directly to stakeholders, and there is less need for third party audit of such data which is digitally tagged as credible using universally accepted labels from a generally accepted taxonomy, and all at lower costs (Seele, 2016).

Industry 4.0 could also be used to improve environmental management accounting initiatives in a number of ways which might encourage greater take up:

- Obtaining previously unobtainable data

- Raising the quality of data through higher accuracy and detail for environmental, efficiency, data assurance and other decision-making purposes

- Improved transfers of data for management control

- Common pool facilitates data extraction for all types of decisions, all types of managers and all types of gatekeepers

- Piggy-back onto existing manufacturing infrastructure which will limit the investment cost

In Industry 4.0 what was invisible and poor quality data about environmental impacts and costs of operations could be made visible or more accurate as a foundation for automated decisions by intelligent machines. Machines operating to real time data would no longer have to wait passively for an operator's decisions and instructions before optimising production schedules, anticipating faults and undertaking maintenance and 
repairs. Instead, relevant and comprehensive digital data provided in real time "... should be able to actively suggest task arrangements and adjust operational parameters to maximise productivity and product quality" (Lee et al., p. 5). For example, in an Industry 4.0 world as support for ISO 14051 Material Flow and Cost Accounting cyber system sensors could be used to monitor the physical material and energy flows, make a virtual copy of the physical flows, and take autonomous decentralised decisions in real time to minimise material use and losses from actual and predicted inefficiencies.

As identified for external environmental accounting data quality for managers can be improved in the digitised advanced manufacturing environment leading to higher productivity. Real time measurement and automatic monitoring of energy costs could increase productivity; energy supply sources could be automated to switch automatically to low or no carbon emissions. "As our society makes the transition towards sustainable energy, smart grids allow volatile energy sources to be incorporated by matching supply and demand in real time in a highly complex energy system" (Kagermann, 2015, p. 27). Davies (2015, p.5) speculates:

"By using advanced analytics in predictive maintenance programmes, manufacturing companies can avoid machine failures on the factory floor and cut downtime by an estimated $50 \%$ and increase production by $20 \%$. Some companies will be able to set up 'lights out' factories where automated robots continue production without light or heat after staff has gone home."

Industry 4.0 could encourage improved transfers of data between silos and in supply chains leading to environmental and monetary gains from improved management. Data to assist with transfers between different departments, or between parties in a supply chain would be available from infrastructure investments in networked digital information and communication technologies.

At the departmental level a proclivity for silo thinking, as observed by Burritt et al. (2011) in the context of corporate responsibilities for carbon management accounting, could potentially be overcome in the fourth industrial revolution through shared real time common source information about transfer pricing (Burritt et al., 2011). Given appropriate algorithms for volumes and prices machines will self-select best courses of action by examining integrated data from sensors about environmental, costing and pricing aspects of performance in an impersonal way.

En route to Industry 4.0 human decision making would be informed by a common pool data base accessible by all, particularly transdisciplinary strategic teams. If through increased digitised connectivity provided by the Internet of Things and Cyber-physical Systems environmental and sustainability managers, in-house environmental lawyers and accountants would have access to shared data about environmental aspects of operations and investments and there would be an increased chance they could work together to use the real time environmental management accounting data and decide in a collaborative way on environmentally sound eco-efficient actions.

A further way in which Industry 4.0 could encourage environmental management accounting initiatives is by recognising the parallel between the data supply chain and eco-efficient supply chain management. For example, water-specific environmental management accounting in the wine supply chain in Australia provides a case in point 
as it requires the collection and communication of water specific data, often by the wine producer in a collaborative relationship (Christ, 2014). Industry 4.0 technologies mean that impacts on relative environmental and monetary performance are more transparent, being located in a commonly accessible data pool.

\section{Discussion - capturing the potential of Industry 4.0 for environmental accounting}

As noted in Overview of industry 4.0 section considerable uncertainty exists over whether or how quickly the world might move into the fourth industrial revolution. Nonetheless given the mounting interest and the large capital investments involved the question arises as to what academics, practitioners and policy makers might do now to try and secure the potential benefits from Industry 4.0 for development of environmental accounting.

\section{Implications for academics}

Academics could help in two main ways. First they could adopt a research agenda to address environmental accounting issues which might be able to be solved in an Industry 4.0 setting and, second, they could explore ways in which environmental accounting education could be improved. The research agenda could consider how external environmental accounting and environmental management accounting could piggy-back on the potential of Industry 4.0 for providing new, more accurate, better quality, real time physical and monetary data about businesses.

It would be of use for academic research to establish the sectors in which Industry 4.0 is likely to have the greatest impact and where environmentally sensitive issues arise as it is in these sectors where improvements in environmental reporting and decision making are likely to be the most effective. To date Industry 4.0 has tended to focus on potential gains for capital intensive industries, such as aviation, oil and gas, transportation, power generation and distribution, manufacturing, healthcare and mining (Deloitte, 2015; General Electric Company and Accenture 2014; Staufen 2016). The environmental accounting literature has looked at industries affecting and affected by environmental issues such as water security and greenhouse gas emissions (Cormier and Magnan, 2015; Deegan and Gordon, 1996). Identifying and exploring overlaps between expected Industry 4.0 impact sectors and environmentally sensitive sectors could be the subject of academic research to help gain the highest leverage for advancement of environmental accounting to improve corporate environmental performance.

A potentially important second strand of academic research would be to examine the size of companies most likely affected by Industry 4.0 as those companies could experience the benefits of faster connectivity and higher quality data and would be suitable targets for increasing the rate of environmental accounting take up. At present the size of companies targeted by Industry 4.0 is not clear. To date much of the potential for Industry 4.0 seems to have been aimed at large, multinational companies (Davies, 2015; Deloitte, 2015). However, it is also argued that small and medium sized enterprises are not but should be involved (General Electric Company and Accenture 2015; Olle and Claus, 2015; Sommer, 2015). Deloitte (2015, p.10) states "Very large manufacturing companies and multinational groups already consider the topic very important. Small 
and medium-sized companies do not yet appear to consider Industry 4.0 to be of great relevance to them even though these companies are most likely to be the big winners from the shift." Small and medium sized enterprises form a central part of most economies and have the opportunity to build smart manufacturing from scratch and implement digital transformation rapidly, rather than rebuilding or retrofitting to integrate data gathering across different units as large businesses need to do (Deloitte, 2015). Constraints on the involvement of smaller companies in current Industry 4.0 initiatives are perceived to include lack of awareness of economic benefits, insufficient resources for establishing intelligently networked processes, and staff not having sufficient knowledge (Olle and Claus, 2015). Unless these challenges are overcome Industry 4.0 investments and developments in larger companies are likely to be the stronger catalyst for development of environmental accounting. If Industry 4.0 is taken up by smaller companies studies could be undertaken to draw attention to the conditions when ecoefficiency measurement and reporting are most likely to succeed, as environmental accounting tools are designed to support decision making by companies of all sizes (Burritt et al., 2002; Herzig et al., 2012).

A third potentially helpful avenue of research could look internally at the impact of Industry 4.0 on roles of and communications between managers with different environmental responsibilities. In discussions of Industry 4.0 much emphasis is placed on physical and cyber aspects of production processes, information flows and the role of production and information technology managers to improve productivity and reduce risk (Van Thienen et al., 2016). Environmental accounting requires monetary measures of performance as well, and although not emphasised at present in the Industry 4.0 literature, research could examine whether and how the connection with physical and eco-efficiency measures could be added at little extra cost.

A fourth research topic could be exploring whether, how and to what extent there is a spin-off in Industry 4.0 for environmental accounting from managers working together collaboratively. Industry 4.0 relies on cross-disciplinary engineering occurring seamlessly through design, development, manufacture and disposal of products and data at each stage of the product life cycle being accessible by all from a single source on the cloud and boosts the need for transdisciplinary thinking which also includes practitioner involvement (Deloitte, 2015). Environmental accounting is transdisciplinary by definition and needs teams of professional with different expertise working together. On water scarcity issues for example, team members include environmental managers who tend to be engineers, accountants, lawyers and meteorologists, working together to identify, measure, optimise and perhaps report environmental and economic performance (Tingey-Holyoak et al., 2014). Comparison of pre- and post- Industry 4.0 structures and processes could identify benefits and potential challenges for environmental accounting take up in the two settings, given the relative availability of accurate real time digital physical engineering, environmental and monetary data.

A fifth research topic area to help ensure benefits of Industry 4.0 are captured for promoting environmental accounting is supply and value chain management. Industry 4.0 emphasises the integration of parties in a supply chain in order to improve processes, data flows, scheduling and trade, economic benefits but does not consider environmental issues per se. Once the mechanisms for integration are in place supply chain collaborators could be able to gain access to real time common pool data to help 
optimise environmental and economic performance. But little research has been conducted into these possibilities. There is, however, no shortage of funding to support installation of the basic Industry 4.0 infrastructure to provide dynamic, real time data at all stages of the value chain (Deloitte, 2015). In Britain in 2012 alone the government provided $£ 170$ (A $\$ 300$ ) million in funds to established or new small and medium sized enterprise suppliers through an Advanced Manufacturing Supply Chain Initiative to high value economic, social and environmental outcomes and demonstrated carbon efficiencies (Davies, 2015). Where considered useful it is but a small step to introduce environmental accounting to help confirm such outcomes and efficiencies, and to report them in real time to external parties.

In summary, a new academic research program could be aimed at establishing how Industry 4.0 might facilitate more accurate, high quality, real time environmental management accounting and external environmental reporting in relevant sectors, company sizes, across different management roles and collaborative settings, as well as in intraorganisational settings such as supply chains.

Once such a research agenda is underway the results could be incorporated into the curricula of undergraduate and postgraduate students as a foundation for providing knowledge of both Industry 4.0 and environmental accounting as a basis for responsible business.

Implications for practitioners and policy makers (professional associations and government) Accountants in practice and in business can help capture the benefits of Industry 4.0 for environmental accounting in a number of ways.

One critical issue is whether practitioners, acting as providers of professional services, are prepared to take on a bigger role than conventional accounting embraces. The emergence of Industry 4.0 and environmental sustainability are two settings within which accounting can broaden its scope, especially through the area of environmental accounting. Raising awareness of the potential changing scope of accounting work is being discussed by professional accounting bodies as part of their thought leadership (Guthrie et al., 2015). Signatures of Industry 4.0 are noted in the context of exponential increases in computer processing power, connected work that can be completed almost anywhere in the world, and automation replacing mundane, repetitive tasks of accounting, audit and taxation (Dawson, 2015) as well as the need to keep on top of environmental sustainability as a hot topic (Cooper, 2015). Professional services firms can be influenced by both or neither. Industry 4.0 is nevertheless addressed by the Big 4 accounting firms, Deloitte (2015), EY (2016), KPMG (2015); PwC (2016), with a focus on increased efficiency and lower cost but none of them mention the environment in the same context. Professional associations also scan for potential future changes to keep their members advised. One element of the professional associations' advice stems through professional development education, and the leading firms gaining knowledge. At this stage little data is available about the promotion of Industry 4.0 by professional accounting associations- another gap for academic research to fill - hence the connections they are making with environmental accounting also are unexplored. Bringing together tools from these two areas will be a challenge, but one which could reap large rewards, for business and the environment. 
To capitalise on aspects of Industry 4.0 environmental accountants will need to be educated at university and trained through ongoing professional development to understand the new digitised data network systems and to appreciate the benefits of digitalisation for obtaining quality and timely data about corporate eco-efficiency and other related concepts. Government regulation might have a part to play in gleaning from Industry 4.0 the best path forward for environmental accounting education and practice. Government is unlikely to have any impact on environmental management accounting which is largely devoid of any external influences and depends on data relevant to management for decision making. If influence is to be brought on companies to adopt environmental accounting in an Industry 4.0 setting it is more likely to spring from funding by government for developing the standards behind language systems in place for recording and transferring data. Perhaps this could be achieved in the digital unified reporting manner outlined by Seele (2016) incorporating physical and monetary data. For example, for financial reporting since 2009 the U.S. Securities and Exchange Commission has required digital XBRL common data repository financial statements from companies. Within Industry 4.0 it could be a small step, at a relatively small expense, to build environmental virtuosity into the data gathering standards which already have a strong emphasis on economic efficiency. Furthermore, the profession could argue that requests made for government funding of Industry 4.0 developments for small and medium-sized enterprises should include the foundations for environmental accounting, working incrementally with carbon emissions reduction, water scarcity, land use changes, etc.

\section{Conclusion}

Industry 4.0 presents a speculative vision of an advanced networked commercial society. Accompanying but currently not included in this vision for more highly digitised industries and trade is the possibility for improved corporate environmental performance and a stronger role for environmental accounting. Based on superior data availability, especially about opportunities for pollution and waste prevention, networked commercial societies of the future could be designed with digital data being made available in real time to monitor and certify optimal corporate environmental and monetary performance. However, there are no guarantees that the current vision for Industry 4.0 will be used to help address environmental crises, except by chance. Better than chance would be investigation by academics, practitioners and policy makers of How Industry 4.0, or the Internet of Things, might be employed to enhance the outcome of environmental accounting initiatives.

The paper raises questions for academics to explore and practitioners and policy makers to consider as Industry 4.0 holds the potential to facilitate better understanding of the value to the business of environmental accounting through greater transparency, reduction of the possibility of greenwash and brownwash, focus on the sectors and size of firms that matter most, etc. The marginal investment cost of such facilitation could be very low as generation of numbers revealing environmental performance for decision making and reporting could piggy-back on the large investments in infrastructure already being made to improve digitisation and connectivity. These investments would be sunk costs as far as environmental accounting is concerned but for those promoting Industry 4.0 could be seen as presenting additional benefits previously not considered. 
Industry 4.0 development provides the background upon which environmental accounting tools could be enhanced. In particular, the tools could bring together measures of environmental and economic performance to demonstrate joint benefits in real time, more accurately and with higher quality data than has been possible before the spread of new digital technologies such as the Internet of Things and Services, and Cyber-physical Systems. Industry 4.0 networking of innovative computer systems channeling operational data to a common base, such as the cloud, for potential interrogation by multiple managers with different professional backgrounds and roles, multiple external stakeholder groups with their own interests and cultures, across multiple countries facing multiple environmental opportunities and concerns potentially holds great potential for securing the benefits of environmental accounting for larger companies. But if the Industry 4.0 vision extends further it has the potential to provide a platform for the take-up of environmental accounting by multitudinous smaller companies. As argued in the paper both present an opportunity and a challenge needing the attention of academics, practitioners and policy makers. Asian countries, particularly China with its heavy investment in Industry 4.0 and concerns over environmental issues associated with growth, might be prime contenders to take up this challenge.

Authors' contributions

The authors contributed equally to the manuscript. Both authors read and approved the final manuscript.

\section{Authors' information}

Professor Dr Roger Burritt is Visiting Professor, Management in the International Food Industry, Faculty of Organic Agricultural Sciences, University of Kassel, Germany; Visiting Professor of Sustainability Business Metrics, Centre for Sustainability Management, Leuphana Universität Lüneburg, Germany; and Visiting Professor of Excellence, Department of Accounting and Finance, University of Zaragoza, Spain. He has conducted research and published widely on Environmental Accounting, especially Environmental Management Accounting.

Dr Katherine Christ is an Academic at the University of South Australia and Research Assistant at the University of Tasmania, Australia with a PhD and specialized research interests in Environmental Management Accounting and the wine industry.

Competing interests

The authors declare that they have no competing interests.

\section{Author details \\ ${ }^{1}$ Management in the International Food Industry, Faculty of Organic Agricultural Sciences, University of Kassel, Steinstraße 19, 37213 Witzenhausen, Hesse, Germany. ${ }^{2}$ Centre for Accounting, Governance and Sustainability, University of South Australia Business School, GPO Box 2471, Adelaide, South Australia 5001, Australia.}

Received: 18 October 2016 Accepted: 4 November 2016

Published: 12 December 2016

\section{References}

Atzori L, lera A, Morabito G (2010) The internet of things: A survey. Comput Netw 54(15):2787-2805

Baur C, Wee D (2015) Manufacturing's next act., Available at: http://www.mckinsey.com/insights/manufacturing/ manufacturings_next_act Accessed 22 July 2016

Brown DL, Dillard JF, Marshall RS (2005) Strategically informed, environmentally conscious information requirements for accounting information systems. J Inf Sys 19(2):79-103

Burritt RL, Hahn T, Schaltegger S (2002) Towards a comprehensive framework for environmental management accounting - Links between business actors and environmental management accounting tools. Aust Account Rev 12(27):39-50

Burritt R, Schaltegger S, Zvezdov D (2011) Carbon Management Accounting: Explaining Practice in Leading German Companies. Aust Account Rev 56(21):80-98

Christ KL (2014) Water management accounting and the wine supply chain: Empirical evidence from Australia. Brit Account Rev 46(4):379-396

Christ KL, Burritt RL (2015) Material flow cost accounting: a review and agenda for future research. J Clean Prod 108: $1378-1389$

Cooper B (2015) Class of 2025: The Future Finance Professional. In: Evans E, Burritt R, Guthrie J (eds) Future Proofing the Profession: Preparing Business Leaders and Finance Professionals for 2025, vol 6, Academic Leadership Series Chartered Accountants Australia and New Zealand/RMIT University., pp 81-87

Cormier D, Magnan M (2015) The economic relevance of environmental disclosure and its impact on corporate legitimacy: An empirical investigation. Bus Strat Envt 24(6):431-450 
Davies R (2015) Industry 4.0. Digitalisation for productivity and growth, Briefing for the European Parliament (PE 568.337) September 2015. European Parliamentary Research Service

Dawson R (2015) What is the Future of Work? In: Evans E, Burritt R, Guthrie J (eds) Future Proofing the Profession: Preparing Business Leaders and Finance Professionals for 2025, vol 6, Academic Leadership Series. Chartered Accountants Australia and New Zealand/RMIT University., pp 25-33

Deegan C, Gordon B (1996) A study of the environmental disclosure practices of Australian corporations. Account Bus Res 26(3):187-199

Deegan C, Rankin M (1996) Do Australian companies report environmental news objectively? An analysis of environmental disclosures by firms prosecuted successfully by the Environmental Protection Authority. Account Audit Account J 9(2):50-67

Deloitte (2015) Industry 4.0. Challenges and solutions for the digital transformation and use of exponential technologies. Deloitte AG, Zurich

Ditz D, Ranganathan J, Banks RD (1999) Green Ledgers. In: Bennett M, James P (eds) The green bottom line: environmental accounting for management; current practice and future trends. Greenleaf, Sheffield

Epstein MJ (1996) Improving environmental management with full environmental cost accounting. Environ Qual Manag 6(1):11-22

EY (2016) The rise of Industry 4.0., Available at: http://performance.ey.com/2015/07/17/the-rise-of-industry-4-0/. Accessed 21 July 2016

General Electric Company and Accenture (2014) Industrial Internet Insights Report for 2015., Available at: https://www. accenture.com/au-en/_acnmedia/Accenture/next-gen/reassembling-industry/pdf/Accenture-Industrial-InternetChanging-Competitive-Landscape-Industries.pdf Accessed 17 July 2016

Germany Trade and Invest (2014) INDUSTRIE 4.0. Smart Manufacturing for the Future. Germany Trade and Invest, Berlin

Gray J, Hughes M (2016) Insight. Industry 4.0: It's The Future, But We've Been There Before. Digital Transformation. Hitashi Consulting, Dallas

Guthrie J, Evans E, Burritt R (2015) Work: Past, Present and Future. In: Evans E, Burritt R, Guthrie J (eds) Future Proofing the Profession: Preparing Business Leaders and Finance Professionals for 2025, vol 6, Academic Leadership Series. Chartered Accountants Australia and New Zealand/RMIT University., pp 9-22

Herzig C, Viere T, Schaltegger S, Burritt RL (2012) Environmental Management Accounting: Case Studies of South-East Asian Companies. Routledge, Abingdon, Oxon, New York

Hrasky S (2011) Carbon footprints and legitimation strategies: symbolism or action? Account Audit Account J 25(1): 174-198

Hsu CW, Lee WH, Chao WC (2013) Materiality analysis model in sustainability reporting: A case study at Lite-On Technology Corporation. J Clean Prod 57:142-151

International Federation of Accountants (IFAC) (2005) International Guidance Document on Environmental Management Accounting. IFAC, New York

International Organization for Standardization (ISO) (2011) ISO 14051, Environmental Management - Material Flow Cost Accounting. General Framework. ISO, Geneva

Kagermann H (2015) Change Through Digitization-Value Creation in the Age of Industry 4.0. In: Albach H, Meffert H, Pinkwart A, Reichwald R (eds) Management of Permanent Change. Springer Fachmedien, Wiesbaden, pp 23-45

Kim EH, Lyon TP (2014) Greenwash vs. brownwash: Exaggeration and undue modesty in corporate sustainability disclosure. Organ Sci 26(3):705-723

Kokubu K, Kitada H (2015) Material flow cost accounting and existing management perspectives. J Clean Prod 108: $1279-1288$

KPMG (2015) Industry 4.0. The fourth industrial revolution. "How does the factory of the future look like?", Available at: http://performance.ey.com/2015/07/17/the-rise-of-industry-4-0/. Accessed 21 July 2016

Lee J, Kao H-A, Yang S (2014) Service Innovation and Smart Analytics for Industry 4.0 and Big Data Environment. Procedia CIRP 16:3-8

Olle W, Claus D (2015) Industry 4.0 Needs SMEs. Chemnitz Automotive Institute (CATI) and CARNET GmbH, Chemnitz Technical University, Chemnitz

Phillips PS, Read AD, Green AE, Bates MP (1999) UK waste minimization clubs: a contribution to sustainable waste management. Resour Conserv Recy 27:217-247

Porter ME, van der Linde C (1995) Green and Competitive: Ending the Stalemate. Harvard Bus Rev 73(5):120-134

PwC (2016) Industry 4.0., Available at: http://www.pwc.com/gx/en/industries/industry-4.0.html Accessed 21 July 2016

Scavone GM (2006) Challenges in internal environmental management reporting in Argentina. J Clean Prod 14(14): $1276-1285$

Schaltegger S, Burritt R (2000) Contemporary environmental accounting: issues, concepts and practice. Greenleaf, Sheffield

Schaltegger S, Burritt R, Petersen H (2003) An introduction to corporate environmental management: Striving for sustainability. Greenleaf Publishing Limited, Sheffield

Searcy C, Elkhawas D (2012) Corporate sustainability ratings: an investigation into how corporations use the Dow Jones Sustainability Index. J Clean Prod 35:79-92

Seele P (2016) Digitally unified reporting: how XBRL-based real-time transparency helps in combining integrated sustainability reporting and performance control. J Clean Prod 136(Part A):65-77

Sommer L (2015) Industrial revolution-industry 4.0: Are German manufacturing SMEs the first victims of this revolution? $J$ Ind Eng Manag 8(5):1512

Staniskis JK, Stasiskiene Z (2006) Environmental management accounting in Lithuania: exploratory study of current practices, opportunities and strategic intents. J Clean Prod 14(14):1252-1261

Staufen AG (2016) China - Industry 4.0 Index 2015. Industry 4.0 and Lean., Available at: http://www.staufen.ag/ fileadmin/hq/survey/STAUFEN.-studie-china-industrie_4_0-index-2015-EN.pdf Accessed 3 May 2016

Tingey-Holyoak J, Pisaniello J, Burritt RL (2014) The need for Engineering Accounting: Identifying current and future demand and supply. Report to the Institute of Chartered Accountants in Australia, Sydney 
US Environmental Protection Agency (US EPA) (1995) Introduction to environmental accounting. US EPA, Washington DC Van Thienen S, Clinton A, Mahto M, Sniderman B (2016) Industry 4.0 and the chemicals industry. Catalyzing transformation through operations improvement and business growth. Deloitte University Press, Oakland, USA.

Viere T, von Enden J, Schaltegger S (2011) Life cycle and supply chain information in environmental management accounting: a coffee case study. In: Burritt RL et al. (eds.), Environmental Management Accounting and Supply Chain Management, Springer Science+Business Media B.V., Dordrecht, Netherlands, pp. 23-40.

Wiedmann T, Barrett J (2010) A review of the ecological footprint indicator-perceptions and methods. Sustain 2(6): $1645-1693$

Wübbeke J, Conrad B (2015) Industrie 4.0: Will German Technology Help China Catch Up with the West? China Monitor 23:1-10

Submit your manuscript to a SpringerOpen ${ }^{\circ}$ journal and benefit from:

- Convenient online submission

- Rigorous peer review

- Immediate publication on acceptance

- Open access: articles freely available online

- High visibility within the field

- Retaining the copyright to your article

Submit your next manuscript at $\boldsymbol{\nabla}$ springeropen.com 